\title{
Culture Optimization for Mass Production of Rhizobium Using Bioreactor Made of Readily Available Materials and Agitated by Air Flow
}

\author{
Most. Farhana Begom, Md. Giush Uddin Ahmed* ${ }^{\circledR}$, Rebeka Sultana, Ferdous Akter \\ Department of Agronomy and Agricultural Extension, University of Rajshahi, Rajshahi, Bangladesh \\ Email: ^ahmedmgu@ru.ac.bd
}

How to cite this paper: Begom, M.F., Ahmed, Md.G.U., Sultana, R. and Akter, F. (2021) Culture Optimization for Mass Production of Rhizobium Using Bioreactor Made of Readily Available Materials and Agitated by Air Flow. Agricultural Sciences, 12, 620-629.

https://doi.org/10.4236/as.2021.126040

Received: April 28, 2021

Accepted: June 15, 2021

Published: June 18, 2021

Copyright $\odot 2021$ by author(s) and Scientific Research Publishing Inc. This work is licensed under the Creative Commons Attribution International License (CC BY 4.0).

http://creativecommons.org/licenses/by/4.0/

\begin{abstract}
Large quantities of Rhizobium leguminosarum by conventional technique are a time-consuming and labor-intensive method of production. The selection of different types of nutrient media for the production of large amounts of rhizobium at low cost, determination of environmental regulators of culture medium and the effect of different levels of air flow into nutrition media have been investigated. Rhizobium cultured in modified air lift bioreactor as improved conventional system using Yeast Extract Mannitol Broth by assessing aeration and agitation in their submerged growth. For selection of suitable nutrient media for Rhizobium before mass production, YMA (Yeast Mannitol Agar), YSA (Yeast Sucrose Agar), YMA + bromthymol blue (BTB), YMA + Congo red (CR) medium was tested. To optimize the growing conditions of different temperatures, $\mathrm{pH}$ levels and salt strengths were investigated. Three air flow speeds at the rate of $0.01,0.05$ and 0.1 VVM for oxygen supply were ensured. A thick off-white bacterial colony was observed on the YMA plate among different culture media. Room temperature $\left(25^{\circ} \mathrm{C}-30^{\circ} \mathrm{C}\right)$, neutral $\mathrm{pH}$ (7.0), low salinity (1\%) was observed to be suitable among the environmental conditions for Rhizobium mass production. The maximum density of Rhizobium was observed using air supply of $0.1 \mathrm{VVM}$ level in bioreactor system. The result seemed that the air supply and agitation was an important growth factor in submerged cultivation. This study provides useful information on large scale production of Rhizobium of interest employing low cost effective modified air lift bioreactor within less time.
\end{abstract}

\section{Keywords}

Rhizobium, Bioreactor, Agitation, Mass Propagation, Bacteria 


\section{Introduction}

In terms of business the term, "large scale production" refers to the production of a commodity on a large scale with a large sized firm. It requires huge investments in plants and machinery. Large scale production can be carried out if the market size is large and expanding. In this research bioreactor for Rhizobium large scale production is usually described in a biochemical sterile environment that capitalizes on liquid nutrient or liquid/air flow and outflow systems, designed for intensive culture and control over micro environmental conditions (agitation, aeration, temperature, and $\mathrm{pH}$ ).

Rhizobia are famous for their potency to embed a symbiosis with legumes. They inhabit root nodules, where they reduce atmospheric nitrogen and make it available to the plant. The Rhizobium bacterial strains in the starter cultures were needed to be grown on a large scale for which their mass production was urgently needed. In order to produce large quantities for a microorganism, the inoculums must be purified and liquid form would be cultured. Next, have to select the culture vessel used for liquid culture. In this case the size of the culture vessel is adjusted as required and productivity depends on vessel size [1]. Environmental requirements for microbial culture vessels have to be ensured.

Mass propagation at a higher rate after isolation of micirobial biofertilizer is a challenging issue. This involves the culturing of large volumes of bacteria to obtain enough material to spectrally characterize an isolated compound. Currently, it is estimated that upwards of $90 \%$ of all culturing experiments in biotechnology are performed through shaken cultures [2]. The benefits of using shaken cultures are numerous and include the ability to culture in high density, a relatively low-cost barrier, and the use of easily accessible equipment. There are, however, a number of drawbacks to using shake flasks [3]. Primarily, shake flasks rely on surface aeration to transfer oxygen into the culture, resulting in low oxygen transfer compared to stirred bioreactors [4]. For natural product researchers, the application of shake flasks for the large-scale cultivation of microorganisms for natural product isolation has additional challenges. Although high-capacity shakers capable of handling numerous flasks at one time are available, they are expensive. This necessitates the use of smaller, cheaper orbital shakers that requires multiple rounds of culturing to generate enough material for compound isolation and characterization [3].

Conventional funnel or balloon shaped glass containers are taken for the purpose of cultivating more bacteria in a short period of time. It is not cost effective as low cost parts are assembled. Agitation of these types of bioreactors is accomplished by the flow of sterile air instead of mechanical stirring. Sometimes fermenters also used; the equipment, which provides the proper environment for the growth of a desired organism. It is generally a large vessel in which, the organism is kept at the required temperature, $\mathrm{pH}$, dissolved oxygen concentration and substrate concentration. A sophisticated fermenter contains $\mathrm{pH}$ regulator, oxygen level regulator, anti-foam device, temperature controller, etc. 
Multifarious field of application needs bulk amount of Rhizobium inoculums. Cultivation of these valuable bacteria in conventional methods is a costly, laborious and time consuming process. It is important to introduce in vitro mass bacterial cultivation methods by introducing any other simple and affordable method. Bioreactor system enabling aeration, agitation and maintaining OD from outside of the system during cultivation that hastens the submerged limitation. Modified air-lift bioreactor is completely offering for plenty production of Rhizobium which costs low and takes only couple of days. Bioreactor yielded liquid state entire biomass can be incorporated with carrier material Ramanujam et al. [5] to meet the ever increasing demand of world focused organic farming. The mass production of the bacterial strain to be utilized as a biofertilizer. Aimed at mass production in full in vitro condition to optimization of culture media, culture conditions including agitation for liquid form of Rhizobium, multiply the Rhizobium largely in modified air-lift photo bioreactor with less time and cost.

\section{Materials and Methods}

\subsection{Optimization of Culture Conditions}

For selection of suitable nutrient media for Rhizobium before mass production YMA (Yeast Mannitol Agar), YSA (Yeast Sucrose Agar), YMA + bromthymol blue (BTB), YMA + Congo red (CR) preparation were used to test the purity of culture. YEMA medium and $6.8 \mathrm{pH}$ was selected as standard for this experiment to find out the optimum temperature for growth of Rhizobium. Difference in the range of growth temperature was investigated by incubation of bacterial cultures in YEM agar at $20^{\circ} \mathrm{C}, 25^{\circ} \mathrm{C}, 30^{\circ} \mathrm{C}$ and $35^{\circ} \mathrm{C}$. To find out the optimum $\mathrm{pH}$ condition for growth $25^{\circ} \mathrm{C}$ temperature was selected as standard. The influence of medium $\mathrm{pH}$ on rhizobial growth was investigated at 5.0, 6.0, 7.0 and 8.0 by using $\mathrm{HCl}$ and $\mathrm{NaOH}$ in a $\mathrm{pH}$ meter after mixing of media ingredients. The salinity tolerance was measured by culturing the bacteria on YEMA medium containing different salt concentration $1 \%, 2 \%, 3 \%, 4 \%(\mathrm{w} / \mathrm{v}) \mathrm{NaCl}$.

\subsection{Preparation of Liquid Media}

Yeast Extract Mannitol Broth media (Vincent, 1970) [6] components were mixed properly and adjusted the $\mathrm{pH}$ to $6.8 \pm 0.02$. All culture media were sterilized at $121^{\circ} \mathrm{C}$ for 20 minutes by autoclaving. All culture vessels, rubber pipes, rubber corks and spargers were also sterilized at $121^{\circ} \mathrm{C}$ for 20 minutes by autoclaving. Selected bacterial strains were grown in slants and transferred to liquid broth to detect the growth of Rhizobium under static and agitation conditions YEMB observed after 3 days of inoculation.

\subsection{Establishment of Rhizobium Culture in Bioreactor System}

Modified Air lift bioreactor was used as an automated culture $2 \mathrm{~L}$ vessel to propagate bulk amount of the Rhizobium inoculants. The modified vessel has 
three outlets with pipes one for air supply into the medium and other two for let out the bubbles and gases to control produced gas pressure. One liter of yeast mannitol broth medium was prepared for each bioreactor system. Sterilized culture media poured into the vessel inside the laminar air flow hood. Then 48 days old Rhizobium cultured into the medium with sterilized pipette.

\subsection{Culture Conditions for Bioreactor System}

For appropriate growing condition of Rhizobium leguminosarum following parameters were applied in bioreactor system that used for mass production of Rhizobium leguminosarum. A set of three bioreactors were used in the preparation to evaluate the need of air supply into the culture medium of Rhizobium cultivation. An air pumper with regulator was entered into the bioreactor system. Three nose of air supplier connected with the outlet of respective bioreactor. Aeration convinced by three speeds of air as 0.01, 0.05, 0.1 VVM (Vessel volume per minute) through air passing by air compressor regulation from outside of system. Another bioreactor system had no air supply as control in the aeration experiment of oxygen necessary. After that sealed all outlet of system with parafilm after rubber band and incubated the system in growth chamber.

\subsection{Estimation of Optical Density (OD)}

Rhizobial growth in broth culture was become opaque in 2 - 3 days. Broth optical density was checked by using spectrophotometer (at $540 \mathrm{~nm}$ ). Values of OD. correlate to number of cells. If OD. values will be high then cells number also will be high [7].

\section{6. pH Test for Purity of Rhizobium Culture}

Fast-growing Rhizobium produce a little acidic compound. After incubation, the $\mathrm{pH}$ was decreased. (Example, $\mathrm{pH}$ before growing $=7.0$, after growing $\mathrm{pH}=6.4$ 6.6). If broth $\mathrm{pH}$ of contaminants [8].

\subsection{Determination of Colony Forming Unit (CFU)}

After 24 - 48 hours of incubation, the plates with different colonies were selected for counting. Counting of colonies was normally done by visual observation. Then total CFU were determinate according to the following equation [7].

$$
\mathrm{CFU}=\frac{\text { Colonies count on an agar plate } \times \text { Amount plated }}{\text { Total dilution of tube }(\text { used to make plate for colony count })}
$$

\section{Results and Discussions}

\subsection{Optimization of Culture Conditions}

The organism was identified with nutrient medium dependence for selection of suitable nutrient medium of Rhizobium before mass production. Rhizobium usually do not absorb CR. BTB containing YMA plate show an alkaline reaction, 
fast growing Rhizobium turn the medium yellow. Noted that growth and color reactions described here were dependent on the strain metabolism on the standard YMA media.

Growth of bacteria on Yeast Extract Mannitol Agar (YEMA) medium indicates their ability to fix atmospheric Nitrogen to the plants (Figure 1). The use of Yeast Extract Mannitol Agar (YEMA) medium for the isolation of Nitrogen fixing (Rhizobia) bacteria was earlier been reported by some workers [9] [10] [11]. After incubation of 2 - 5 days the bacteria was grown well on YEMA + Congo red medium, white thick colony color and medium color remained as pink. The colony grown on medium YEMA + bromthymol blue grows as well, the medium color of green turned yellowish after Rhizobium grows. This indicates that the isolate was a fast-grower and acid producer as reported by [12].

Highest growth of Rhizobium on YEMA plates were shown $2.3 \times 10^{9} \mathrm{CFU} / \mathrm{ml}$ in $25^{\circ} \mathrm{C}$ and $2 \times 10^{9} \mathrm{CFU} / \mathrm{ml}$ in $30^{\circ} \mathrm{C}$ (Figure 2). The culture which incubated at $20^{\circ} \mathrm{C}$ was not satisfactory. Culture incubated at $35^{\circ} \mathrm{C}$ was unfavorable for Rhizobium species. Allison and Minor [13] reported most species of Rhizobia were showed the optimum growth rate lies between $29^{\circ} \mathrm{C}$ and $31^{\circ} \mathrm{C}$. Beijerinck [14] stated that room temperature was the most favorable for clover bacteria. Laurent [15] obtained the compatible growths at $22^{\circ} \mathrm{C}$ to $26^{\circ} \mathrm{C}$; at $30^{\circ} \mathrm{C}$. The growth was no better than at the lower range.

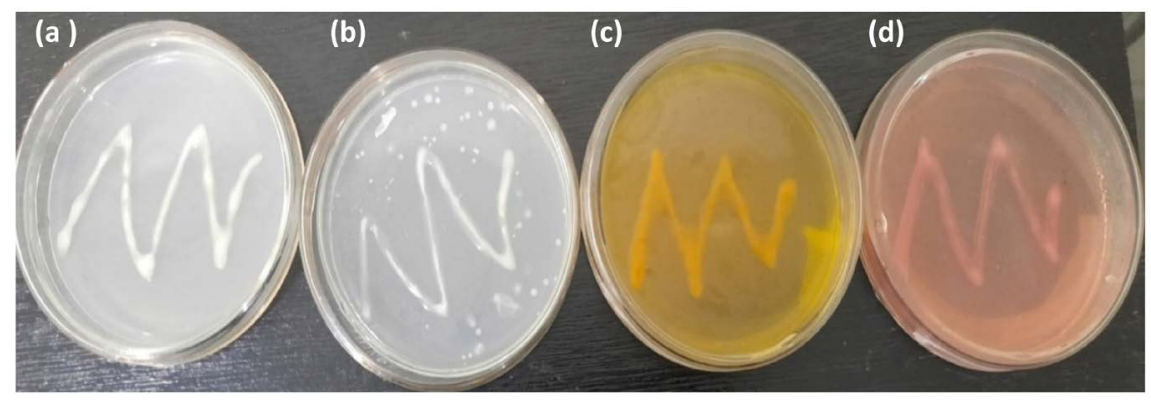

Figure 1. Growth performance of Rhizobium in different media, (a) = YMA, (b) = YSA, (c) = YMA + bromthymol blue (BTB), (d) = YMA + Congo Red (CR).

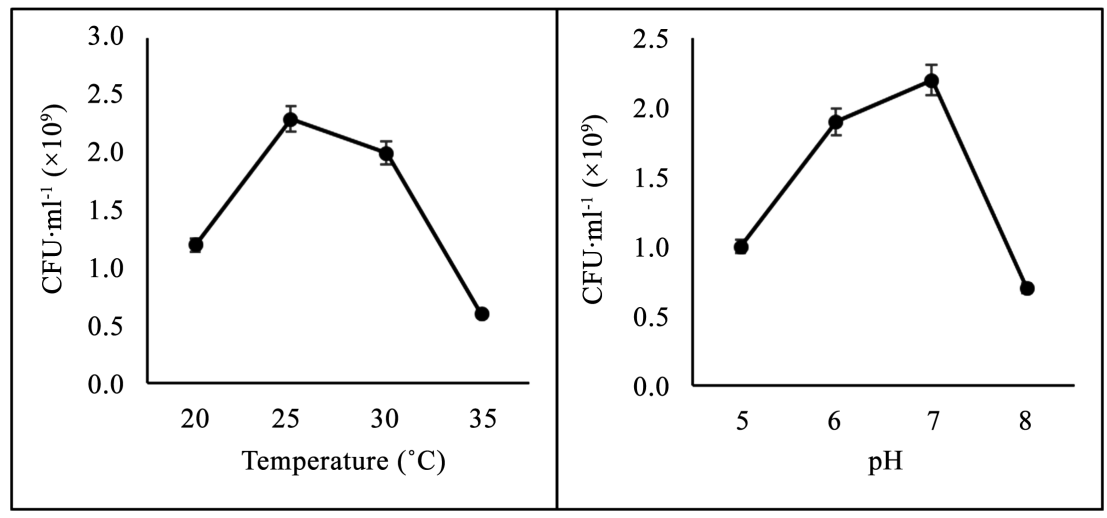

Figure 2. Colony forming unite of Rhizobium on YEMA at different temperature and $\mathrm{pH}$ level. 
The response of Rhizobium growth rate to nutrient medium was observed between pH 5 - 8 (Figure 2). The maximum growth was found in $7 \mathrm{pH}$ adjusted culture and the lowest $\mathrm{CFU} / \mathrm{ml}$ found in $8 \mathrm{pH}$ treating culture medium the $\mathrm{CFU}$ was $0.7 \times 10^{9} 6 \mathrm{pH}$ culture media was influence the Rhizobium to grow well after highest growth of $7 \mathrm{pH}$. The $\mathrm{pH}$ of the medium and broth during growth of isolates was changed from 7.0 to 6.0 , thus showing the production of acid which is the characteristic of Rhizobium to produce acid during growth [16] [17].

\subsection{Salt Tolerance of Rhizobium}

To determine tolerance in saline environments strains of rhizobia showed different growth rate at different concentration of $\mathrm{NaCl}$, maximum growth rate was observed at $1 \%(\mathrm{w} / \mathrm{v}) \mathrm{NaCl}$ and minimal at $4 \%(\mathrm{w} / \mathrm{v}) \mathrm{NaCl}$ (Table 1). Jida and Assefa [18] also reported high tolerance to $\mathrm{NaCl}$ the Rhizobium could grow well with $1 \% \mathrm{NaCl}$. However, at higher concentrations, the percentage of tolerant isolate decreased with increasing salt concentration. The isolated bacteria were showed no growth on the YEMA with $2 \% \mathrm{NaCl}$, thus confirming the Rhizobium [19].

\subsection{Response of Agitation for Large Scale Production}

Environmental suitability is created by agitation for micro-organisms. The colour of culture medium was changed with agitated condition in drowned cultivation as off-white to brown (Figure 3, Table 2). Poor growth was observed in non-agitated condition in large vessel due to using only static medium conditions and it was denser than the medium of static condition. Highest optical density was observed in agitated vessel because of bacterial growth was improved due to agitation plays a role in dissolving oxygen through nutrition. Usually agitated or shaked culture did not allow the bacteria to be clumped on the surface and distributed properly into whole medium.

Table 1. Effect of $\mathrm{NaCl}$ concentration on Rhizobial growth.

\begin{tabular}{cc}
\hline Concentration of $\mathrm{NaCl}$ & Growth \\
\hline $1 \%$ & $+++\mathrm{ve}$ \\
$2 \%$ & $++\mathrm{ve}$ \\
$3 \%$ & $+\mathrm{ve}$ \\
$4 \%$ & $-\mathrm{ve}$ \\
\hline
\end{tabular}

${ }^{\star}$ Legend: $+++=$ excellent growth; $++=$ less growth; $+=$ poor growth; $-=$ no growth.

Table 2. Influence of agitation on mass production of Rhizobium spp.

\begin{tabular}{cccc}
\hline Culture conditions & Colour response & Growth performance & OD \\
\hline Agitation & Brown & Good & 1.969 \\
Non-Agitation (Static) & Light yellow & Poor & 0.984 \\
\hline
\end{tabular}




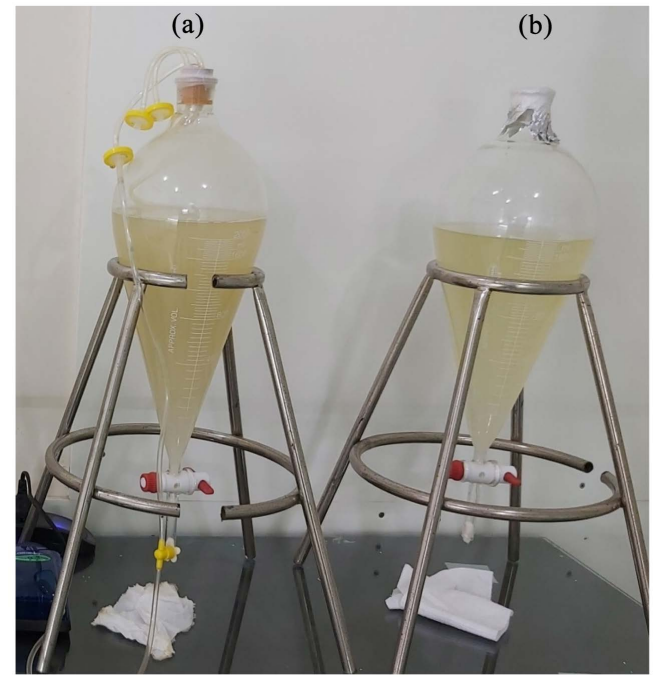

Figure 3. Influence of agitation on growth of Rhizobium (a) = agitation, (b) = without agitation.

\subsection{Effect of Air Flow Rate on Mass Production of Rhizobium}

Bioreactors are widely used for microbial mass production in laboratory conditions. Rhizobium are very sensitive to changes in the culture environmental conditions, such as aeration, agitation, nutrients, and $\mathrm{pH}$. Influence of air flow on Rhizobium multiplications are shown in Figure 4. Minimal growth was observed in non-aerated condition in large vessel due to using only static medium conditions. In the absence of agitation through liquid nutrients, bacterial colonies usually form only on the surface of nutrients due to lack of oxygen. Maximum bacterial growth was found using $0.1 \mathrm{VVM}$ air supply (Figure 5). The rate of growth of Rhizobium is similar to the rate of increase in air supply through liquid nutrition. Air circulation occurred at the rate of $0.01,0.05,0.1 \mathrm{VVM}$ whereas 0.1 VVM air passing influence for highest cell growth of Rhizobium (1.769) when optical density at $540 \mathrm{~nm}$ after 72 hours. The medium speed of 0.05 VVM resulted 1.410 O.D. at 72 hours after.

The color of culture medium was changed with the passing of air speed in drowned cultivation as off-white to light brown (Table 3). The brown color of $0.10 \mathrm{VVM}$ aerated bioreactor is relatively darker than other bioreactors which indicates that $0.10 \mathrm{VVM}$ air supply increases the production of Rhizobium. The supply of air causes bubbles in the culture media, causing mild agitation in the media, which causes all the media to be used for growth of Rhizobium. The non-aerated bioreactor was found light off-white color, due to absence of agitation.

\subsection{Purity of Production Media}

As fast-growing Rhizobium produce acids media $\mathrm{pH}$ tends to decrease with the increasing bacteria. Before inoculation we can see the media $\mathrm{pH}$ was $6.8 \pm 0.02$ (Figure 6). The number of bacteria increases and at the same time the media $\mathrm{pH}$ 


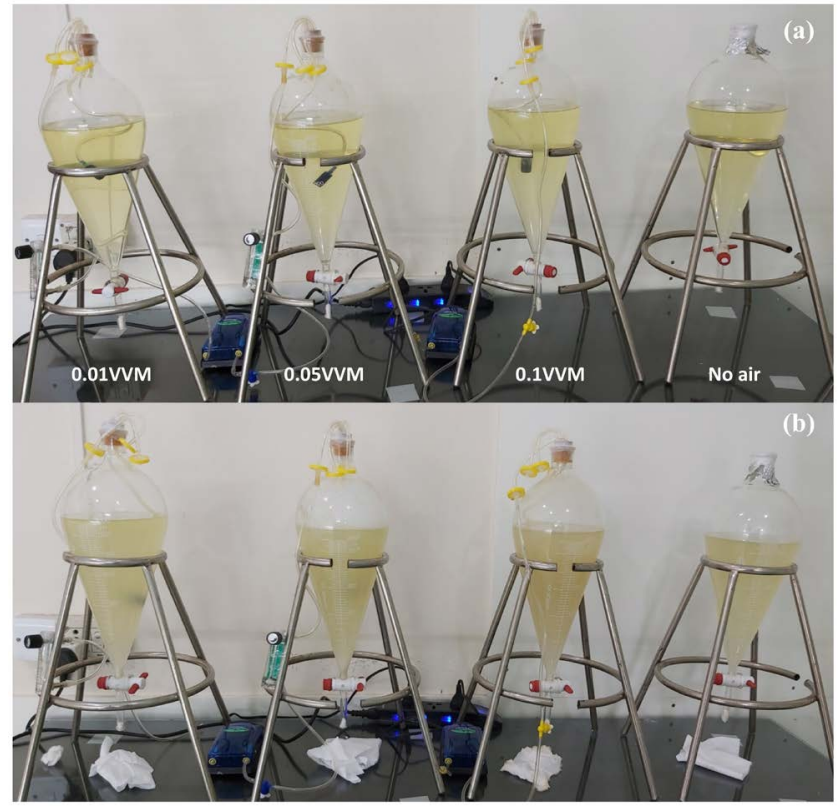

Figure 4. Impact of aeration on mass production of Rhizobium using bioreactor. (a) $=00$ hours and (b) $=72$ hours after inoculation.

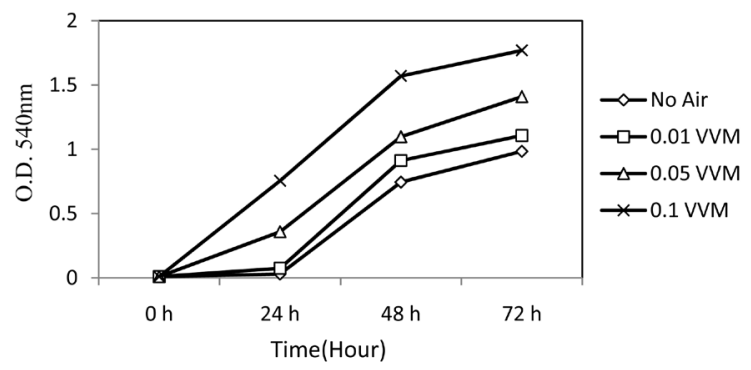

Figure 5. Influence of different air flow level on growth of Rhizobium spp.

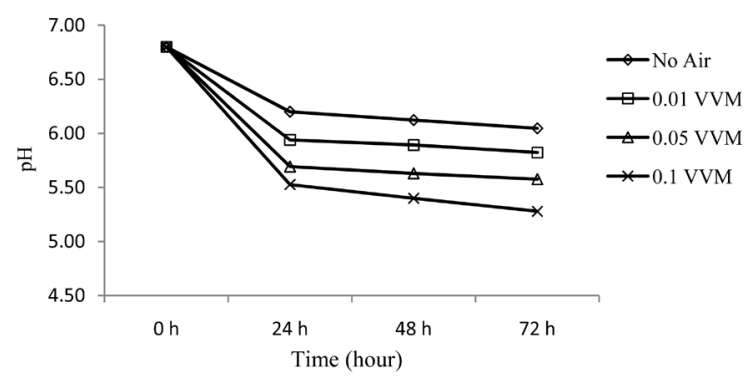

Figure 6. Observation of $\mathrm{pH}$ at different time for growth of Rhizobium spp.

Table 3. Influence of air supply on media color and growth status of Rhhizobium.

\begin{tabular}{ccc}
\hline Air supply (VVM) & Culture color & Growth \\
\hline $0.00($ No air) & Light yellow & Poor \\
0.01 & Off white & Medium \\
0.05 & Light brown & Good \\
0.10 & Brown & Good++
\end{tabular}


decreases. The $\mathrm{pH}$ of the medium and broth during growth of isolates was changed from 7.0 to 6.0 , thus showing the production of acid which is the characteristic of Rhizobium to produce acid during growth [16] [17]. Rhizobia showed growth in 3 days and turned the yeast mannitol agar media containing bromothymol blue to yellow color showing that all were fast growers and acid producer [20].

\section{Conclusion}

This research was an effective process of producing large amounts of Rhizobium in a short time at a low cost. In this study, biofertilizers produced by Rhizobium was found to be potent since it could be active at $0.1 \mathrm{VVM}$ air supply shows good results. Therefore, it was found that biofertilizers produced on lab scale might be beneficial tools for agriculture and environment. In the future, emphasis can be placed on the proper and economical utilization of abundantly present Rhizobium.

\section{Conflicts of Interest}

The authors declare no conflicts of interest regarding the publication of this paper.

\section{References}

[1] Bissonnette, N., Lalnde, R. and Bordeleau, L.M. (1986) Large-Scale Production of Rhizobium meliloti on Whey. Applied and Environmental Microbiology, 52, 838-841. https://doi.org/10.1128/aem.52.4.838-841.1986

[2] Buchs, J. (2001) Introduction to Advantages and Problems of Shaken Cultures. Biochemical Engineering Journal, 7, 91-98. https://doi.org/10.1016/S1369-703X(00)00106-6

[3] Theodore, C.M., Loveridge, S.T., Crews, M.S., Lorig-Roach, N. and Crews, P. (2019) Design and Implementation of an Affordable laboratory-Scale Bioreactor for the Production of Microbial Natural Products. Engineering Reports, 1, e12059. https://doi.org/10.1002/eng2.12059

[4] Betts, J.I. and Baganz, F. (2006) Miniature Bioreactors: Current Practices and Future Opportunities. Microbial Cell Factories, 5, Article No. 21. https://doi.org/10.1186/1475-2859-5-21

[5] Ramanujam, B., Prasad, R.D., Sriram, S. and Rangeswaran, R. (2010) Mass Production, Formulation, Quality Control and Delivery of Trichoderma for Plant Disease Management. The journal of Plant Protection Sciences, 2, 1-8.

[6] Vincent, J.M. (1970) A Manual for the Practical Study of Root Nodule Bacteria. Blackwell, Scientific Publications, Oxford.

[7] Dash, S.K., Chakraborty, S.P., Mandal, D. and Roy, S. (2012) Isolation and Characterization of Multidrug-Resistant Uropathogenic Escherichia coli from Urine Sample of Urinary Tract Infected Patients. International Journal of Life Science and Pharmaceutical Research, 2, 25-39.

[8] Ajay, V., Patel, A., Banjare, U., Kumar, S. and Singh, R.K. (2017) Standardization of Isolation Technique of Rhizobium from Root Nodules of Lentil. International Jour- 
nal of Current Microbiology and Applied Sciences, 6, 132-134.

https://doi.org/10.20546/ijcmas.2017.611.017

[9] Pervin, S., Jannat, B., Sanjee, S. and Farzana, T. (2017) Characterization of Rhizobia From Root Nodule and Rhizosphere of Lablab Purpureus and Vigna sinensis in Bangladesh. Turkish Journal of Agriculture, 5, 14-17.

https://doi.org/10.24925/turjaf.v5i1.14-17.743

[10] Mujahidy, J., Hassan, M., Rahman, M. and Rashid, A.N.M. (2013) Isolation and Characterization of Rhizobium spp. and Determination of Their Potency for Growth Factor Production. International Research Journal of Biotechnology, 4, 117-123.

[11] Rajpoot, P. and Panwar, K.S. (2013) Isolation and Characterization of Rhizobia and Their Effect on Vigna radiata Plant. Octa Journal of Biosciences, 1, 69-76.

[12] Alemayehu, W. (2009) The Effect of Indigenous Root-Nodulating Bacteria on Nodulation and Growth of Faba Bean (Vicia Faba) in the Low-Input Agricultural Systems of Tigray Highlands, Northern Ethiopia. Momona Ethiopian Journal of Science, 1, 30-43. https://doi.org/10.4314/mejs.v1i2.46047

[13] Allison, F.E. and Minor, F.W. (1989) The Effect of Temperature on the Growth Rates of Rhizobia. Journal of Bacteriology, 39, 365-371. https://doi.org/10.1128/jb.39.4.365-371.1940

[14] Beijeiinck, M.W. (1888) Die Bacterien der Papilionaceenknbllchen. Botan Zeitung, 46, 741-50.

[15] Laurent, E. (1891) Recherches sur les nodosites radicales des Ldgumineuses. Annales de P Institut Pasteur Microbiology, 5, 105-139.

[16] DeVries, G.E., Veld, I. and Kijne, P. (1980) Production of Organic Acids in Pisum sativum Root Nodules as Results of Oxygen Stress. Plant Science Letters, 20, 115-123. https://doi.org/10.1016/0304-4211(80)90030-9

[17] Huang, B.L., Lv, C.Q., Wu, B. and Fan, L.Q. (2007) A Rhizobia Strain Isolated from Root Nodule of Gymnosperm Podocarpus macrophyllus. Science China Life Sciences, 50, 228-233. https://doi.org/10.1007/s11427-007-0034-0

[18] Jida, M. and Assefa, F. (2012) Phenotypic Diversity and Plant Growth Promoting Characteristic of Mesorhizobium Species Isolated from Chickpea (Cicer arietinum L.) Growing Areas Ethiopia. African Journal of Biotechnology, 11, 7483-93.

[19] Temam, A.H. and Alemayehu, L.A. (2017) Isolation and Characterization of Rhizobia from Rhizospher and Root Nodule of Cowpea, Elephant and Lab Lab Plants. International Journal of Novel Research in Interdisciplinary Studies, 4, 1-7.

[20] Shah, N.H., Hafeez, F.Y., Asad, S., Hussain, A. and Malik, K.A. (1995) Isolation and Characterization of Indigenous Rhizobium leguminosarum bv. viciae nodulating Lens culinaris Medic from Four Pakistani Soils. Pakistan Journal of Botany, 211-220. 